\title{
Patient-Centered Care and Associated Factors among Adult Admitted Patients in South Wollo Public Hospitals, Northeast Ethiopia
}

\author{
Rahel G/egziabher', Gashaw Andargie Biks $\mathbb{D}^{2}$, Nigusu Worku $\mathbb{D}^{2}$, Bekalu Endalew $\mathbb{D}^{3}$, \\ Endalkachew Dellie $\mathbb{D}^{2}$ \\ 'Department of Public Health, College of Medicine and Health Sciences, Dilla University, Dilla, Ethiopia; ${ }^{2}$ Department of Health System and Policy, \\ Institute of Public Health, College of Medicine and Health Sciences, University of Gondar, Gondar, Ethiopia; ${ }^{3}$ Department of Public health, College of
} Medicine and Health Sciences, Debre Markos University, Debre Markos, Ethiopia

Correspondence: Bekalu Endalew, Email bekiehsm@gmail.com

Background: The US Institute of Medicine's "quality chasm" report defined patient-centered care as care that is respectful of and responsive to individual patient preferences, needs, and values, and ensuring that patient values guide all clinical decisions. Services that lack patient-centered care lead to unimproved health status, decreased patient and family satisfaction, and poor patient outcomes. Therefore, this study aimed to assess patient-centered care and associated factors among admitted patients in South Wollo public hospitals in northeast Ethiopia.

Methods: This was a facility-based quantitative cross-sectional study design supplemented with qualitative analysis conducted from February 10 to March 10, 2020 across South Wollo public hospitals. A total of 618 admitted patients were selected using multistage systematic random sampling and interviewed using a structured questionnaire. Five health professionals were selected for in-depth interviews. Binary logistic regression analysis was carried out to identify associated variables, and potential confounders were controlled using a multivariate logistic regression model, and $P<0.05$ was considered significant.

Results: Overall, $60.9 \%(95 \%$ CI $57.1 \%-64.5 \%)$ of patients received patient-centered care. Age 25-35 years (AOR 0.39, 95\% CI 0.32-0.64) years, rural residence (AOR 2.61, 95\% CI 1.62-4.02), social well-being (AOR 2.34, 95\% CI 1.45-3.78), perceived high quality of care (AOR 3.69, 95\% CI 2.07-6.04), length of stay (AOR 0.13, 95\% CI 0.02-0.79), and routine checkups (AOR 1.92, 95\% CI 1.15-3.13) were variables significantly associated with patient-centered care.

Conclusion: This study revealed that among admitted patients, three in five received patient-centered care. Age, residence, social well-being, length of stay, perceived quality of care, and routine checkups were significantly associated with patient-centered care. Therefore, working on provider improvements in providing consultation and facilitation and decreasing length of stay to improve patient-centered care is needed.

Keywords: patient-centered care, public hospitals, South Wollo zone, Ethiopia

\section{Introduction}

The US Institute of Medicine's "quality chasm" report defined patient-centered care as care that is respectful of and responsive to individual patient preferences, needs, and values, and ensuring that patient values guide all clinical decisions. ${ }^{1}$ A patient-centered approach hastens interactions in which clinicians and patients engage in two-way sharing of information, explores patients' values and preferences, helps patients and their families make clinical decisions, facilitates access to appropriate care, and enables patients to follow through with often difficult behavioral changes needed to maintain or improve health. ${ }^{2}$

Patient-centered care enables patients to participate actively in all aspects of their care, such as choices about treatment and self-management, resulting in better adherence to medications and improved chronic disease control without higher costs, which helps to decrease length of stay. ${ }^{3,4}$ It also improves well-being of patients through directly 
reducing anxiety and depression and indirectly by building trust and social support, promoting patient self-efficacy, and addressing disparities. ${ }^{5,6}$ According to the Picker Institute, patient-centered care has eight dimensions: respect for the patient's values, preferences, and expressed needs, information and education, access to care, emotional support to relieve fear and anxiety, involvement of family and friends, continuity and secure transition between health-care settings, physical comfort, and coordination of care. ${ }^{7}$

In low- and middle-income countries, 5.7-8.4 million deaths are attributed to poor-quality of health care each year. A lack of patient-centered care contributes to poor quality through loss to follow-up, unnecessary spread of disease, and decreased medication adherence in health systems. ${ }^{8}$ Nonetheless, in African health institutions there are limited data on patient-centered care. ${ }^{9}$ Provision of health-care services in Ethiopia is more biomedical than biopsychosocial: $71 \%$ of health-care providers admitted to failing to deliver compassionate and respectful care services in Ethiopia in 2015. ${ }^{9,10}$

A study conducted in Tigray region revealed that more than half the patients who received services from health facilities had not experienced patient-centered care. ${ }^{11}$ A lack of patient-centered care leads to unimproved health status, decreased patient and family satisfaction, and poor patient outcome, resulting in high readmission rates, increased average length of stay, increase mortality, poor chronic disease management, and increased cost. ${ }^{4}$ However, provision of care in developing countries, including Ethiopia, is focused on the needs and desires of health-care professionals, particularly physicians. ${ }^{12,13}$

There is limited information on patient-centered care and factors associated with it. As such, international studies have explored patient-centered care from staff and health workers' perspectives to identify key factors associated with its provision. Data from the patient's perspective can optimize health-care delivery. ${ }^{14,15}$ Therefore, this study aimed to assess patient-centered care and associated factors among admitted patients in South Wollo public hospitals, northeast Ethiopia.

\section{Methods}

\section{Study Design and Setting}

This institution-based cross-sectional study supported by qualitative data was conducted from February 10 to March 10, 2020 in four public hospitals of South Wollo zone. South Wollo has a population of 2,718,842 and 17 districts with ten public hospitals and 129 health centers. All public hospitals of this zone deliver health services, including inpatient care. ${ }^{16}$ All patients aged $\geq 18$ years who were admitted and discharged from the selected hospitals and five health professionals were included in this study, while patients who were discharged from intensive care units (ICU) or who discharged themselves were excluded.

\section{Sample Size and Sampling Procedure}

The sample size was determined using a single population-proportion formula by assuming a proportion $(P)$ of patientcentered care of $74 \%$ (from a pilot study at an Ataye primary hospital in northern Shewa), a 5\% margin of error $(d), 5 \%$ nonresponse rate and two design effects: $n=(Z a / 2)^{2}(P)(1-P) /(d)^{2}$. The result was 618 . Five health professionals (three physicians and two nurses) were selected for in-depth interviews.

Multistage systematic random sampling was employed to select study participants. Of the ten public hospitals in South Wollo, four public hospitals $(40 \%)$ were randomly selected for this study using a lottery method. Hospitals were stratified into medical, surgical, and gynecological wards and there were 3,240 eligible admitted adult patients. Finally, proportional allocation were done in each ward and among selected hospitals using systematic random sampling. Respondents were interviewed on discharge using a pretested interviewer-administered questionnaire.

\section{Measurements and Variables}

Patient-centered care was the outcome variable of this study. Sociodemographic characteristics (age, sex, residence, educatio, marital status, occupation, and income), relationship factors (consultation, empathy, health care-provider facilitation), health-related factors (insurance, frequency of visits, routine checkups, perceived quality of care, and length of stay) and patient-related factors (perceived waiting time, perceived severity of illness, social well-being, prior illness experiences, and perceived involvement of care) were independent variables. 
Patient-centered care was measured on eight dimensions (patient preference 7, education and communication 4, physical comfort 5 , access to care 5 , emotional support 4 , continuity and transition care 4 , coordination and integrated care 4, and involvement of family or friends 3 ) with total of 36 Likert scale questions ( 1 [strongly disagree] to 5 [strongly agree]). Patients who scored above the mean regarded as receiving patient-centered care (labeled 1) and below the mean as not receiving patient-centered care (labeled 0$)^{7}$

\section{Data-Collection Tools and Procedure}

Data were collected using the pretested interviewer administered questionnaire, which had been developed based on previous research. ${ }^{7,17,18}$ This covered sociodemographic characteristics, the eight dimensions of patient-centered care, patient-perceived involvement in care, health-care service, and the patient-provider relationship, and an open-ended questionnaire were used to collect data through in-depth interviews of selected health professionals in the study area. Five diploma- and two BSc-qualified nurses were recruited for data collection and supervision, respectively.

\section{Data Quality Control}

The questionnaire was prepared in English and translated into Amharic (the local language) and back to English by language experts to maintain consistency. Prior to data collection, 1 day's training was given to data collectors and supervisors on the study objectives, data-collection instruments, techniques, and producers. Pretesting was done on 39 patients (5\%) at an Ataye primary hospital and necessary amendments made. The consistency and completeness of data were checked by the principal investigator and supervisors on a daily basis. The reliability of the tool was checked by investigators, with Cronbach's $\alpha$ for measuring patient-centered care of 0.97 , consultation and empathy-related questions 0.73 , and patient decision-making involvement 0.78 , indicating good reliability.

\section{Data Processing and Analysis}

Quantitative data were transferred to Epi Info 7 and exported to SPSS 23 for cleaning, coding, and analysis. Descriptive measures were computed to summarize participants' sociodemographic characteristics and patient-centered care. Bivariate and multivariate logistic regression analysis was used to assess association between each independent variable and patient-centered care. Independent variables with $P<0.2$ on bivariate logistic regression were used for multivariate logistic regression analysis. AORs with $95 \%$ CIs and $P<0.05$ were used to reveal associations between explanatory and dependent variables. Variables with $P<0.05$ were considered significant. Model fitness was checked using the HosmerLemeshow goodness-of-fit test $(P=0.57)$ and multicollinearity checked using the variance-inflation factor. A factor $<10$ and tolerance $>0.1$ were regarded as absence of multi-collinearity. The audio-recorded qualitative interviews were transcribed verbatim and translated from Amharic into English by the first author. Translations were also done by data collectors to ensure that the participants' original meanings were fully captured and OpenCode 4.3 was used for analysis of the qualitative data.

\section{Ethics Approval and Consent}

Ethics approval was obtained from the University of Gondar Research and Ethical Review Committee, College of Medicine and Health Sciences (IPH/837/06/2012). In addition, letters of authorization from South Wollo Zone Health Department and hospital administrators were obtained before contacting participants. Participants were then fully briefed about the study's purpose and benefits, and written informed consent was obtained for both data collection and publication. Confidentiality was maintained through anonymity, and privacy measures were taken to preserve the rights of participants throughout the research, including with regard to publication. Finally, participants were asked about their willingness to join the study. Any participant willing to engage in the study and those who wanted to stop an interview at any time were allowed to do so. This study was conducted in accordance with the Declaration of Helsinki. 


\section{Results}

\section{Sociodemographic Characteristics of Respondents}

A total of 611 patients participated, for a response rate of $98.8 \%$. Mean age was $40.4 \pm 15.8$ years. A majority (330, 54\%) of respondents were male, and $371(60.9 \%)$ had had no education. More than half $(315,51.6 \%)$ respondents were urban dwellers and more than two-fifths farmers (Table 1).

\section{Patient Centered-Care Dimensions}

Overall, 60.9\% (95\% CI 57.1\%-64.5\%) of patients received patient-centered care. More than $65 \%$ received care based on their needs and preferences and got emotional support from their care providers. Most of the health-care providers said that patients' preferences and needs were well understood and respected. They disagree on not providing the wrong care and not the patient's preferred type, because patients coming to the hospital requested both necessary and unnecessary services for their health problems.

One patient wanted to have an X-ray not related to their illness and asked directly if they could come to the hospital for this.

I advised them that an X-ray was not necessary for their illness. (30-year-old respondent)

Table I Sociodemographic characteristics of the study participants $(n=6 I I)$

\begin{tabular}{|c|c|c|c|}
\hline & Category & $\mathbf{n}$ & $\%$ \\
\hline \multirow[t]{2}{*}{ Sex } & Male & 330 & 54 \\
\hline & Female & 281 & 46 \\
\hline \multirow[t]{3}{*}{ Age, years } & $18-34$ & 259 & 42.4 \\
\hline & $35-64$ & 276 & 45.2 \\
\hline & $>64$ & 76 & 12.4 \\
\hline \multirow[t]{2}{*}{ Residence } & Urban & 315 & 51.6 \\
\hline & Rural & 296 & 48.4 \\
\hline \multirow[t]{4}{*}{ Education } & None & 371 & 60.9 \\
\hline & Primary school & 86 & 14.1 \\
\hline & Secondary school & 85 & 13.6 \\
\hline & Diploma and above & 69 & 11.4 \\
\hline \multirow[t]{2}{*}{ Marital status } & Married & 370 & 60.6 \\
\hline & Unmarried & 241 & 39.4 \\
\hline \multirow[t]{2}{*}{ Income, ETB } & $<5,200$ & 555 & 90.8 \\
\hline & $\geq 5,200$ & 28 & 4.6 \\
\hline \multirow[t]{5}{*}{ Occupation } & Government & 69 & 11.3 \\
\hline & Merchant & 136 & 22.3 \\
\hline & Farmer & 262 & 42.9 \\
\hline & Daily labor & 101 & 16.5 \\
\hline & Other* & 43 & 7 \\
\hline
\end{tabular}

Note: *Private employer/student. 
Table 2 Dimensions of patient-centered care $(n=611)$

\begin{tabular}{|c|c|c|c|}
\hline & Category & $\mathbf{n}$ & $\%$ \\
\hline \multirow[t]{2}{*}{ Respect patient need and preference } & Yes & 400 & 65.5 \\
\hline & No & 211 & 34.55 \\
\hline \multirow[t]{2}{*}{ Information, education, and communication } & Yes & 318 & 51.9 \\
\hline & No & 293 & 48.1 \\
\hline \multirow[t]{2}{*}{ Physical comfort } & Yes & 302 & 50.6 \\
\hline & No & 309 & 49.4 \\
\hline \multirow[t]{2}{*}{ Access to care } & Yes & 341 & 55.8 \\
\hline & No & 270 & 44.2 \\
\hline \multirow[t]{2}{*}{ Emotional support } & Yes & 399 & 65.3 \\
\hline & No & 212 & 34.7 \\
\hline \multirow[t]{2}{*}{ Continuity of care } & Yes & 395 & 65 \\
\hline & No & 214 & 35 \\
\hline \multirow[t]{2}{*}{ Coordination of care } & Yes & 399 & 65 \\
\hline & No & 212 & 35 \\
\hline \multirow[t]{2}{*}{ Family or friend involvement } & Yes & 333 & 45.5 \\
\hline & No & 278 & 54.5 \\
\hline \multirow[t]{2}{*}{ Patient-centered care } & Yes & 372 & 60.9 \\
\hline & No & 239 & 39.1 \\
\hline
\end{tabular}

Not only as a health professional but also as a human being, providing emotional support to patients is very important. (37-yearold respondent)

Two-fifths (45.5\%) of care was delivered with the involvement of patients' friends and families, and more than half $(50.6 \%)$ the patients received their care in physical comfort.

Involvement of family or friends is based on the patient's decision, but may necessitate other considerations depending on the disease's condition. For example, TB patients can easily transmit the disease, so disclosure of this to the family for their protection is preferable. (29-year-old respondent, physician)

In this hospital, we have changed the old beds to keep our patients comfortable. (34-year-old respondent) (Table 2)

\section{Service Delivery and Patient-Related Characteristics}

Of the 611 respondents, $379(62 \%)$ had community health insurance and $425(69.6 \%)$ had visited the health facility one to five times. Most respondents $(412,67.4 \%)$ perceived that they had been consultat and had received empathy from the health-care provider and $412(32.6 \%)$ received good provider facilitation (Table 3).

\section{Factors Associated with Patient-Centered Care}

Bivariate analysis showed that sex, residence, age, marital status, education, length of stay, perceived quality of care, social well-being, decision-making involvement, provider facilitation, having community health insurance, consultation 
Table 3 Service delivery and patient-related characteristics $(n=6 I I)$

\begin{tabular}{|c|c|c|c|}
\hline & Category & $\mathbf{n}$ & $\%$ \\
\hline \multirow[t]{3}{*}{ Frequency of health-facility visits } & New & 153 & 25 \\
\hline & Fewer than five & 425 & 69.6 \\
\hline & Five and more & 33 & 5.4 \\
\hline \multirow[t]{2}{*}{ Community health insurance } & Yes & & \\
\hline & No & 232 & 38 \\
\hline \multirow[t]{2}{*}{ Perceived quality of care } & High & 154 & 25.2 \\
\hline & Low & 457 & 74.8 \\
\hline \multirow[t]{4}{*}{ Length of stay, days } & $1-5$ & 19 & 3.1 \\
\hline & $6-10$ & 122 & 20 \\
\hline & $11-15$ & 284 & 46.5 \\
\hline & $>15$ & 186 & 30.4 \\
\hline \multirow{2}{*}{$\begin{array}{l}\text { Patient-perceived severity of } \\
\text { disease }\end{array}$} & Yes & 511 & 83.6 \\
\hline & No & 100 & 16.4 \\
\hline \multirow[t]{2}{*}{ History of admissions } & Yes & 214 & 35 \\
\hline & No & 397 & 65 \\
\hline \multirow{2}{*}{$\begin{array}{l}\text { Perception of physician } \\
\text { competence }\end{array}$} & Yes & 541 & 88.5 \\
\hline & No & 70 & 11.5 \\
\hline \multirow[t]{2}{*}{ Decision-making involvement } & Yes & 239 & 39.1 \\
\hline & No & 372 & 60.9 \\
\hline \multirow[t]{2}{*}{ Social well-being } & Poor & 300 & 49.1 \\
\hline & Good & 311 & 50.9 \\
\hline \multirow[t]{2}{*}{ Consultation and empathy } & Poor & 199 & 32.6 \\
\hline & Good & 412 & 67.4 \\
\hline \multirow[t]{2}{*}{ Health care-provider facilitation } & Yes & 230 & 37.6 \\
\hline & No & 381 & 62.4 \\
\hline \multirow[t]{2}{*}{ Routine checkups } & Yes & 214 & 35 \\
\hline & No & 397 & 65 \\
\hline
\end{tabular}

and empathy, routine checkups, patient-perceived severity of disease, and history of hospital admission were significant predictors of patient-centered care. Multivariate analysis illustrated that age, residence, length of stay, social well-being, perceived quality of care, routine checkups, and provider facilitation remained significantly associated with patientcentered care.

Accordingly, the odds of receiving patient-centered care were higher for patients who lived rurally than their counterparts (AOR 2.61, 95\% CI 1.62-4.02). Patients age 35-64 years were 61\% less likely to have receiv patientcentered care than those aged 18-34 years (AOR 0.39, 95\% CI 0.32-0.64). Patients with high social well-being were 
Table 4 Bivariate and multivariate logistic regression analysis of patient-centered care and associated factors $(n=6 \mathrm{II})$

\begin{tabular}{|c|c|c|c|c|}
\hline & \multicolumn{2}{|c|}{ Patient-centered care } & \multirow[t]{2}{*}{ COR $(95 \% \mathrm{Cl})$} & \multirow[t]{2}{*}{ AOR $(95 \% \mathrm{Cl})$} \\
\hline & Yes & No & & \\
\hline \multicolumn{5}{|l|}{ Residence } \\
\hline Urban & 179 (56.8\%) & $136(43.2 \%)$ & 1 & 1 \\
\hline Rural & $193(65.2 \%)$ & $103(34.8 \%)$ & $1.42(1.03-1.97)$ & $2.61(1.62-4.02)^{*}$ \\
\hline \multicolumn{5}{|l|}{ Education } \\
\hline None & 199 (53.6\%) & $172(46.4 \%)$ & 1 & 1 \\
\hline Primary & $59(68.6 \%)$ & $27(31 \%)$ & $1.89(1.15-3.11)$ & $1.28(0.64-2.55)$ \\
\hline Secondary & $70(82.3 \%)$ & $15(17.7 \%)$ & $4.03(2.23-7.30)$ & $1.23(0.53-2.59)$ \\
\hline Diploma and above & $44(63.7 \%)$ & $25(36.3 \%)$ & $1.52(0.89-2.59)$ & $0.98(0.45-2.24)$ \\
\hline \multicolumn{5}{|l|}{ Age, years } \\
\hline $18-34$ & $175(67.5 \%)$ & $84(32.5 \%)$ & 1 & 1 \\
\hline $35-64$ & $151(54.7 \%)$ & $125(45.3 \%)$ & $0.58(0.4 \mathrm{I}-0.82)$ & $0.39(0.32-0.64)^{* * *}$ \\
\hline$\geq 64$ & $46(60.5 \%)$ & $30(39.5 \%)$ & $0.74(0.43-|.2|)$ & $0.63(0.30-1.32)$ \\
\hline \multicolumn{5}{|c|}{ Prior hospital admission } \\
\hline Yes & $150(64.3 \%)$ & $83(35.7 \%)$ & $1.27(0.9 \mid-1.78)$ & $1.57(0.97-2.52)$ \\
\hline No & $222(58.7 \%)$ & $\mid 56(4 \mid .3 \%)$ & I & 1 \\
\hline \multicolumn{5}{|l|}{ Routine checkups } \\
\hline Yes & $152(7 \mid \%)$ & $62(29 \%)$ & $1.97(1.38-2.8 I)$ & $1.90(1.15-3.13)^{*}$ \\
\hline No & $220(55.4 \%)$ & $177(44.6 \%)$ & I & 1 \\
\hline \multicolumn{5}{|l|}{ Severity of disease } \\
\hline Yes & 299 (58.5\%) & $212(48.5 \%)$ & $0.5(0.32-0.84)$ & $0.93(0.83-1.20)$ \\
\hline No & $73(73 \%)$ & $27(27 \%)$ & I & I \\
\hline \multicolumn{5}{|c|}{ Perceived quality of care } \\
\hline Yes & $315(68.9 \%)$ & $142(31.1 \%)$ & $3.78(2.28-5.53)$ & $3.69(2.07-6.04)^{* *}$ \\
\hline No & $57(37 \%)$ & $97(63 \%)$ & 1 & 1 \\
\hline \multicolumn{5}{|l|}{ Length of stay, days } \\
\hline $1-5$ & 15 (78.9\%) & $4(21.9 \%)$ & I & 1 \\
\hline $6-10$ & $80(65.6 \%)$ & $42(34.4 \%)$ & $0.5 I(0.16-1.63)$ & $0.34(0.06-2.14)$ \\
\hline $11-15$ & $181(63.7 \%)$ & $103(36.3 \%)$ & $0.47(0.15-1.47)$ & $0.27(0.04-1.60)$ \\
\hline$>15$ & $96(51.6 \%)$ & $90(48.4 \%)$ & $0.28(0.09-0.89)$ & $0.13(0.023-0.79)^{*}$ \\
\hline \multicolumn{5}{|c|}{ Health care-provider facilitation } \\
\hline Yes & $169(73.4 \%)$ & $61(26.6 \%)$ & $2.43(1.7 I-3.47)$ & $1.80(1.08-3.00)^{*}$ \\
\hline No & $203(53.3 \%)$ & $178(46.7 \%)$ & 1 & 1 \\
\hline
\end{tabular}


Table 4 (Continued).

\begin{tabular}{|c|c|c|c|c|}
\hline & \multicolumn{2}{|c|}{ Patient-centered care } & \multirow[t]{2}{*}{ COR $(95 \% \mathrm{Cl})$} & \multirow[t]{2}{*}{ AOR $(95 \% \mathrm{Cl})$} \\
\hline & Yes & No & & \\
\hline \multicolumn{5}{|c|}{ Social well-being } \\
\hline Good & $215(69.1 \%)$ & $96(30.9 \%)$ & $2.04(1.67-2.84)$ & $2.34(1.45-3.78)^{*}$ \\
\hline Poor & $157(52.3 \%)$ & |43(47.7\%) & 1 & 1 \\
\hline
\end{tabular}

Notes: $* * P<0.01 ; * P<0.05 ;$ I, reference.

2.34 times more likely to have received patient-centered care than their counterparts (AOR 2.34, 95\% CI 1.45-3.78). The odds of patient-centered care were higher for patients who perceived their care to be of high quality than those who perceived it to be of low quality (AOR 3.69, 95\% CI 2.07-6.04).

In addition, receipt of patient-centered care for those whose length of stay was $>15$ days was $87 \%$ times less likely than for those whose whose length of stay was $>5$ days (AOR $0.13,95 \%$ CI $0.02-0.79$ ). The odds of patient-centered care were higher for patients who received routine checkups than those did not (AOR 1.90, 95\% CI 1.15-3.13). The odds of patient-centered care were higher among patients who received provider facilitation than their counterparts (AOR 1.8, 95\% CI 1.08-3; Table 4).

\section{Discussion}

This study aimed to determine the magnitude of patient-centered care and associated factors among admitted patients in public hospitals of northeast Ethiopia. In sum, 60.9\% (95\% CI 57.1\%-64.5\%) received patient-centered care. This indicated that the remaining $39 \%$ had not received disease- or technology-centered care respectful of and responsive to individual patient preferences, needs, and values. This finding is higher than that from a cross-sectional study done in Tigray regional state, which found $54.5 \% .{ }^{11}$ This difference might be due to differences in measurement, study design, and study period. The Tigray study measured patient-centered care with a 17 -item tool, while this study measured patient-centered care on eight dimensions with 36 questions. Our finding is also lower than the pilot study at the Ataye primary hospital and another study in Austria and the Netherlands. ${ }^{19}$ This discrepancy could be due to differences in socioeconomic status, study design and period, and health-care systems.

We found that patient-centered care was less likely among adult patients than younger patients, in line with a US study. This might be due to differences between younger and older patients in patient-provider communication, ${ }^{20}$ which implies greater information needs among younger patients than older. Patients who resided rurally received more patientcentered care than urban dwellers. This could be due to rural patients being more contented with simple help during care and urban patients being more informed. Patients who went for routine checkups were more likely to receive patientcentered care than those who did not, consistent with a US study. ${ }^{20}$ This might be due to the former having established a relationship with their providers and increased involvement in decision-making regarding their healths.

Good consultation and empathy was more highly associated with patient-centered care than poor consultation and empathy, similar to an Italian study found health-provider empathy to be significantly associated with patient-centered care. ${ }^{21}$ A US study showed that higher levels of perceived empathy during consultations were related to higher levels of patient-centered care. ${ }^{17}$ This could be due to health care providers approach as friend and feel the patient feeling like them. Moreover, patients with high social well-being received more patient centered care than those with low social wellbeing in this study, which is supported by a Dutch study. ${ }^{19}$ This could due to patients with better social-well-being understanding their provider and problems and express their preferences more. 


\section{Strengths and Limitations}

This was the first study of this nature conducted in a public hospital in Ethiopia. We used eight dimensions to measure patient-centered care more widely. Participants were interviewed in separate areas to reduce social desirability bias but social desirability bias may be a limitation of this study.

\section{Conclusion}

This study revealed that among admitted patients, three in five received patient-centered care. Length of stay, social wellbeing, perceived quality of care, consultation and empathy, age, residence, health care-provider facilitation, and routine checkups were significantly associated with patient-centered care. Therefore, the Federal Ministry of Health should give thorough attention to improving patient-centered care by making a positive influence on factors that are believed to be important enablers of the service.

\section{Data Sharing}

Data will be available upon reasonable request from the corresponding author.

\section{Acknowledgments}

The authors would like to thank the University of Gondar Institute of Public Health for providing us the opportunity to conduct this research. In addition, our gratitude goes to the South Wollo Zone Health Department and all hospitals involved for their cooperative and providing the necessary information. Also, we are grateful to our study participants for providing the necessary information and the data collectors for collecting the data carefully.

\section{Author Contributions}

Endalkachew Dellie (assistant professor), Bekalu Endalew, Rahel G/egziabher, and Gashaw Andargie Biks (professor), and Nigusu Worku made significant contributions to the work reported, whether in conception, study design, execution, acquisition of data, analysis and interpretation, or all these areas, took part in drafting, revising, or critically reviewing the article, gave final approval to the version to be published, have agreed on the journal to which the article has been submitted, and agree to be accountable for all aspects of the work.

\section{Funding}

None.

\section{Disclosure}

The authors declare that they have no conflicts of interest for this work.

\section{References}

1. Plsek P; Institute of Medicine. Crossing the Quality Chasm: A New Health System for the 21st Century. Washington, DC: National Academies Press; 2001.

2. Epstein RM, Fiscella K, Lesser CS, et al. Why the nation needs a policy push on patient-centered health care. Health Aff. 2010;29(8):1489-1495. doi: $10.1377 /$ hlthaff.2009.0888

3. Kaplan SH, Greenfield S, Ware J. Impact of the doctor-patient relationship on the outcomes of chronic disease. In: Communicating with Medical Patients. Sage Publications; 1989:228-245.

4. Oates J, Weston WW, Jordan J. The impact of patient-centered care on outcomes. Fam Pract. 2000;49(9):796-804.

5. Epstein RM, Street RL. Patient-centered communication in cancer care: promoting healing and reducing suffering; 2007.

6. Saha S, Beach MC, Cooper LA. Patient centeredness, cultural competence and healthcare quality. J Natl Med Assoc. 2008;100(11):1275-1285. doi:10.1016/S0027-9684(15)31505-4

7. Cramm JM, Nieboer AP. Validation of an instrument for the assessment of patient-centred care among patients with multimorbidity in the primary care setting: the 36-item patient-centred primary care instrument. BMC Fam Pract. 2018;19(1):1-10. doi:10.1186/s12875-018-0832-4

8. National Academies of Sciences, Engineering, and Medicine. Crossing the global quality chasm: improving health care worldwide. National Academies Press; 2018.

9. De Man J, Mayega RW, Sarkar N, et al. Patient-centered care and people-centered health systems in sub-Saharan Africa: why so little of something so badly needed? Int J Person Center Med. 2016;6(3):162-173. 
10. Barry MJ, Edgman-Levitan S. Shared decision making — the pinnacle of patient-centered care. N Engl J Med. 2012;366(9):780-781. doi:10.1056/ NEJMp1109283

11. Berhe H, Gigar G. Status of patient centered care in Tigrai regional state: patients perspective; 2017.

12. Mabasa MN. Bridging the gap in South Africa. Bull World Health Organ. 2010;88:803-804. doi:10.2471/BLT.10.021110

13. Berwick DM. Lessons from developing nations on improving health care. BMJ. 2004;328(7448):1124-1129. doi:10.1136/bmj.328.7448.1124

14. Jarrar MT, Minai MS, Al-Bsheish M, et al. Hospital nurse shift length, patient-centered care, and the perceived quality and patient safety. Int J Health Plann Manage. 2019;34(1):e387-e396. doi:10.1002/hpm.2656

15. Jarrar MT, Al-Bsheish M, Aldhmadi BK, et al. Effect of practice environment on nurse reported quality and patient safety: the mediation role of person-centeredness. In: Healthcare. Multidisciplinary Digital Publishing Institute; 2021.

16. Population Census Commission. Summary and statistical report of the 2007 population and housing census: population size by age and sex. Federal Democratic Republic of Ethiopia, Population Census Commission; 2008.

17. Kamimura A, Weaver S, Armenta B, et al. Patient centeredness: the perspectives of uninsured primary care patients in the United States. Int J Care Coord. 2019;22(1):19-26.

18. Oladapo OT, Iyaniwura CA, Sule-Odu AO. Quality of antenatal services at the primary care level in southwest Nigeria. Afr J Reprod Health. 2008;12(3):71-92.

19. Kuipers SJ, Cramm JM, Nieboer AP. The importance of patient-centered care and co-creation of care for satisfaction with care and physical and social well-being of patients with multi-morbidity in the primary care setting. BMC Health Serv Res. 2019;19(1):13.

20. Singh S, Evans NT, Williams M, et al. Influences of socio-demographic factors and health utilization factors on patient-centered provider communication. Health Commun. 2018;33(7):917-923.

21. Casu G, Gremigni P, Sommaruga M, et al. The Patient-Professional Interaction Questionnaire (PPIQ) to assess patient centered care from the patient's perspective. Patient Educ Couns. 2019;102(1):126-133. doi:10.1016/j.pec.2018.08.006

\section{Publish your work in this journal}

Patient Preference and Adherence is an international, peer-reviewed, open access journal that focusing on the growing importance of patient preference and adherence throughout the therapeutic continuum. Patient satisfaction, acceptability, quality of life, compliance, persistence and their role in developing new therapeutic modalities and compounds to optimize clinical outcomes for existing disease states are major areas of interest for the journal. This journal has been accepted for indexing on PubMed Central. The manuscript management system is completely online and includes a very quick and fair peer-review system, which is all easy to use. Visit http://www.dovepress.com/testimonials.php to read real quotes from published authors.

Submit your manuscript here: https://www.dovepress.com/patient-preference-and-adherence-journal 